\title{
MASS TRANSFER COEFFICIENTS IN CROSS-FLOW ULTRAFILTRATION
}

\author{
G.B. van den BERG*, I.G. RÁCZ and C.A. SMOLDERS \\ Department of Chemical Technology, University of Twente, P.O. Box 217, 7500 AE Enschede \\ (The Netherlands)
}

(Received August 10, 1988; accepted in revised form February 9, 1989)

\begin{abstract}
Summary
Usually, in concentration polarization models, the mass transfer coefficient is an unknown parameter. Also, its variation with changing experimental circumstances is in question. In the literature, many relationships can be found to describe the mass transfer coefficient under various conditions, as well as various corrections for deviating behaviour during ultrafiltration. To obtain reliable mass transfer coefficient relations directly from experimental data, two methods were tested: a method using the osmotic pressure difference during an ultrafiltration experiment, and a method based on the variation in observed retention when cross-flow velocities are changed. The osmotic pressure method appeared to be too insensitive for changing experimental circumstances (according to theoretical considerations). The velocity variation method appeared to be much more useful, although the error in the mass transfer coefficients obtained can be rather large owing to experimental and fitting uncertainties. Therefore the traditional mass transfer relations used in ultrafiltration may be as reliable as (and much more easy to use then) the velocity variation method. The velocity variation method can probably still be used in practice, however, when one or more of the parameters needed in the conventional mass transfer coefficient relations is unknown.
\end{abstract}

\section{Introduction}

Most models used in the description of concentration polarization phenomena during cross-flow membrane filtration require the knowledge of a mass transfer coefficient. Examples are the boundary layer resistance model [1], the osmotic pressure model [2] and the gel layer model [3]. Such an expression for the mass transfer coefficient should be able to represent the effect of changing conditions in systems that are used for membrane filtration. The value of the mass transfer coefficient $k$ can most generally be calculated from Sherwood relations, which are often represented as:

$S h=k d_{\mathrm{h}} D=p R e^{q} S c^{r}$

where $d_{\mathrm{h}}$ is the hydraulic diameter of the system, $D$ is the diffusion coefficient,

*Present address: Unilever Research Laboratory, Colworth House, Sharnbrook, Bedford MK44 $1 \mathrm{LQ}$, England. 
$R e$ is the Reynolds number $\left(R e=\rho v d_{\mathrm{h}} / \eta\right), S c$ is the Schmidt number $(S c=\eta$ ) $[\rho D])$ and $p, q$ and $r$ are adjustable parameters. Usually, the description of the mass transfer coefficient is given for laminar and turbulent conditions separately. This does not imply that there are only two relationships for the mass transfer coefficient. In the literature many different values for $p, q$ and $r$ can be found depending on the operating conditions (laminar/turbulent conditions), the value of the Reynolds and Schmidt numbers and the origin of the models.

In a recent review by Gekas and Hallström [4], no fewer than 27 different Sherwood relations were given for turbulent flow of Newtonian fluids in pipes or flat ducts. Adding the Sherwood relations for non-Newtonian fluids, as well as the relations for the laminar flow case, it will be clear that choosing a relationship that describes a certain system accurately is very difficult.

The relations mostly used in today's membrane literature are [5]:

laminar flow conditions, where the length of the entry region is $L^{*}=0.029 d_{\mathrm{h}} \operatorname{Re}$

$L<L^{*}$ (Grober); $S h=0.664 R e^{0.5} S c^{0.33}\left(d_{\mathrm{h}} / L\right)^{0.33}$

$L>L^{*}$ (Graetz-Leveque); $S h=1.86 R e^{0.33} S c^{0.33}\left(d_{\mathrm{h}} / L\right)^{0.33}$

turbulent flow conditions ( $R e>2000-4000)$

$S c<1$ (Chilton-Colburn or Dittus-Boelter); $S h=0.023 R e^{0.8} S c^{0.33}$

$1 \leqslant S c \leqslant 1000$ (Deissler); $S h=0.023 R e^{0.875} S c^{0.25}$

$S c>1000$ (Harriott-Hamilton); $S h=0.0096 R e^{0.91} S c^{0.35}$

Apart from the large number of different relations, more fundamental problems can be expected: most of the relations mentioned were developed, not for membrane filtration, but for mass transfer in non-porous systems, or were derived from heat transfer-mass transfer analogies.

In the literature, many corrections have been proposed to adapt the value of mass transfer coefficients, now used in the film model, to more realistic (ultra-)filtration circumstances, which include the presence of a layer of increased concentration due to concentration polarization. Apart from papers on specific aspects of the mass transfer coefficient, a number of papers described the problems more generally. An overview of these comments is given here.

- The Sherwood number is linear in $f^{\mathrm{m}}$ ( $f$ is the friction factor), $S c^{\frac{1}{3}}$ (for $S c>1000$ ) and the Reynolds number ( $\mathrm{Sh} \sim f^{\mathrm{m}} \operatorname{ReSc^{\frac {1}{3}}}$ ) [4]. The friction factor $f$ is usually described by Blasius' formula; in the case of turbulent flow conditions the friction factor is:

$f \approx \operatorname{Re}^{-0.25}$ for $10^{4}<R e<10^{5}$

and 
$f \approx R e^{-0.20}$ for $R e>10^{5}$

However, Blasius' formula is valid only for smooth non-porous surfaces, whereas membranes are porous and often rather rough on a microscopic scale. Furthermore, in the literature the value given for $m$ can be found as 0.5 (eddy diffusivity and surface renewal models) or 1.0 (e.g., in the experimental heatmass transfer analogies). Therefore, the Sherwood number is considered to depend on $R e^{0.75}$ to $R e^{0.90}$.

- The effect of variation in properties (increasing viscosity or changing diffusivity and density as a result of increasing concentrations near the membrane interface) has been used by Nakao et al. [6] to obtain a better agreement with experimentally determined mass transfer coefficients. Gekas [4] used a correction factor $\left(S c / S c_{\mathrm{w}}\right)^{0.11}$ based on heat transfer analogies $\left(S c_{\mathrm{w}}\right.$ is the wall Schmidt number).

- The effect of suction during filtration experiments is twofold: suction stabilizes the laminar flow pattern near the membrane interface, and therefore the laminar-turbulent transition region is shifted, e.g., from $R e=2100$ to $R e=4000$ [7], and furthermore the mass transfer coefficient is enhanced.

The well-known Stewart correction for high mass transfer rates $(=$ flux $)$ [8],

$k^{\prime} / k_{0}=\left[J_{\mathrm{v}} / k_{0}\right] /\left[1-\exp \left(-J_{\mathrm{v}} / k_{0}\right)\right]$

describes the enhanced mass transfer coefficient $k^{\prime}$, when suction occurs, used in

$J_{\mathrm{v}}=k^{\prime}\left(C_{\mathrm{m}}-C_{\mathrm{b}}\right) /\left(C_{\mathrm{m}}-C_{\mathrm{p}}\right)$

compared with the value $k_{0}$ for mass transfer without suction, used in

$J_{\mathrm{v}}=k_{0}\left(C_{\mathrm{m}}-C_{\mathrm{b}}\right) /\left(C_{\mathrm{m}}-C_{\mathrm{p}}\right)$

The Stewart correction can also be derived easily from eqns. (10) and (12), which have not and have, respectively, been corrected for the transport towards the membrane:

$J_{\mathrm{v}}=k_{0} \ln \left[\left(C_{\mathrm{m}}-C_{\mathrm{p}}\right) /\left(C_{\mathrm{b}}-C_{\mathrm{p}}\right)\right]$

So, as a consequence, the mass transfer coefficient relations from the literature, which were derived from experiments without suction, should be used without further corrections when the usual concentration polarization equation (eqn. 12) is applied.

- The use of mass transfer relations derived from reverse osmosis experiments can also be erroneous because normally there is a large difference in Schmidt numbers $(S c=\eta / \rho D)$ [4]. For reverse osmosis of salt solutions $S c \approx 600$, while in ultrafiltration of protein solutions $S c>10,000$. Furthermore, 
the effect of variation in properties due to concentration polarization can be expected to be much larger during ultrafiltration than during reverse osmosis.

- The effect of a limited effective area for filtration may be considerable in the case of membranes with a low surface porosity. The surface porosity can be very low indeed for ultrafiltration membranes; values as low as $0.3 \%$ are reported [9]. At such low porosities the build-up of a concentration polarization layer will be very irregular.

- The experimental fluxes for colloidal suspensions are often up to two magnitudes higher than predicted by the film model only [10]. The dependence on the cross-flow velocity $v$ is usually stronger than $v^{0.33}$ for laminar conditions and $v^{0.8}$ for turbulent conditions. The explanation for this behaviour is an increased back-diffusion of particles due to the "pinch effect" or radial migration. This migration occurs as a result of the non-uniform shear field near the membrane, and brings the particles to an equilibrium position away from the membrane interface.

The number of different relationships for the mass transfer coefficient $k$ and the numerous corrections for non-ideal behaviour make it impossible to predict exactly which value the mass transfer coefficient will have. A precise prediction of $k$ is necessary because of the great impact which small deviations in $k$ will have on, e.g., the concentration at the membrane interface and the osmotic pressure difference, when the osmotic pressure model is used. The exponential and power type equations will magnify a small error in the value of $k$ to large deviations in the osmotic pressure and flux; e.g., when the observed retention $\mathscr{R}_{\text {obs }}=1-C_{\mathrm{p}} / C_{\mathrm{b}}=1$ we have:

$C_{\mathrm{m}}=C_{\mathrm{b}} \exp \left(J_{\mathrm{v}} / k\right)$

$\Pi=(R T / M)\left(C_{\mathrm{m}}+B_{2} C_{\mathrm{m}}^{2}+B_{3} C_{\mathrm{m}}^{3}+\ldots\right)$

and

$J_{\mathrm{v}}=(\Delta P-\Delta \Pi) /\left(\eta_{\mathrm{o}} R_{\mathrm{m}}\right)$

It can be concluded that the large number of experimental variables and corrections to existing mass transfer relations provide good reasons for directly determining the mass transfer coefficient experimentally.

Having regard to the available literature, the variables which will influence the value of the mass transfer coefficient can be expected to be: the applied pressure $\Delta P$, the cross-flow velocity $v$, the flux $J_{v}$, the type of solute, the hydraulic dimensions of the module and the characteristics of the membrane (e.g., $\mathscr{R}_{\text {obs }}$ and the hydrophilicity).

The aim of this work is to show two different methods to determine the mass transfer coefficient semi-empirically: the osmotic pressure model and the velocity variation method will be used. Comparisons between the results of these different methods mutually, and with the frequently used mass transfer rela- 
tions from the literature, will be included. The two models which are used to calculate the value of the mass transfer coefficient from the experiments will be described in the theoretical section, as well as some results obtained by other researchers. It is realized that other, newly developed, models for describing concentration polarization and mass transfer currently exist. However, these models are not very suitable for everyday application because of the many equations and the (rather complex) way of solving the integrals involved, e.g., Ref. [7].

\section{Theory}

Both the velocity variation method and the osmotic pressure model describe the concentration polarization phenomenon by the film theory, which usually starts from the basic equation

$\partial C / \partial t+J_{\mathrm{v}} \partial C / \partial x=\partial(D \partial C / \partial x) / \partial x$

Using the right initial and boundary conditions, it can be deduced that

$J_{\mathrm{v}}=(D / \delta) \ln \left[\left(C_{\mathrm{m}}-C_{\mathrm{p}}\right) /\left(C_{\mathrm{b}}-C_{\mathrm{p}}\right)\right]$

where the quantity $D / \delta$ is defined as the mass transfer coefficient $k$. When the observed retention $\mathscr{R}_{\mathrm{obs}}\left(=1-C_{\mathrm{p}} / C_{\mathrm{b}}\right)$ equals unity, eqn. (17) becomes:

$J_{\mathrm{v}}=k \ln \left(C_{\mathrm{m}} / C_{\mathrm{b}}\right)$

\section{The osmotic pressure method}

The build-up of concentration profiles and the resulting osmotic pressure differences during an ultrafiltration experiment can be expected to be as represented in Fig. 1. The total osmotic pressure difference across the membrane is $\Delta \Pi_{\mathrm{tot}}=\Delta \Pi_{\mathrm{bl}}+\Delta \Pi_{\mathrm{b}}-\Delta \Pi_{\mathrm{p}}$, which is almost equal to the well-known equation $\Delta \Pi_{\mathrm{tot}}=\Pi_{\mathrm{m}}-\Pi_{\mathrm{p}} \approx \Pi_{\mathrm{m}}$. When the relatively small osmotic pressures of the bulk

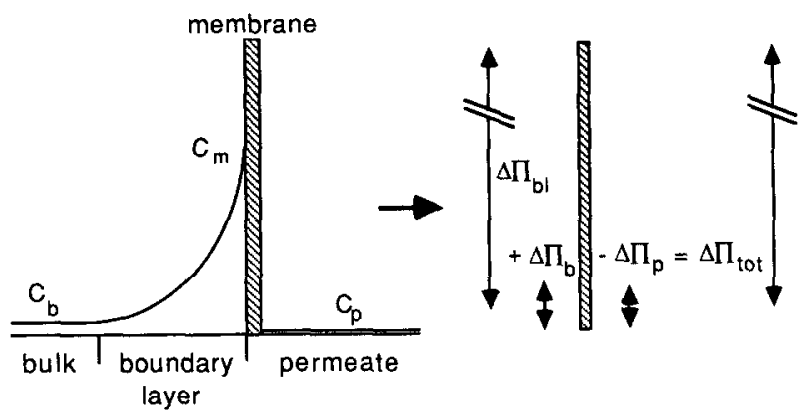

Fig. 1. A schematic view of the concentration profile near the membrane interface and the resulting osmotic pressure differences, where $\Delta \Pi=\Delta \Pi_{\text {tot }} \approx \Delta \Pi\left(C_{\mathrm{m}}\right)$. 
$\left(\Delta \Pi_{\mathrm{b}}\right)$ and the permeate $\left(\Delta \Pi_{\mathrm{p}}\right)$ are neglected, the osmotic pressure difference can be calculated directly from the concentration at the membrane interface only, or conversely, the concentration at the membrane interface wall $C_{\mathrm{m}}$ can be calculated from the osmotic pressure difference $\Delta I I$.

From flux measurements during ultrafiltration of a certain solution, together with the data on the pure water fluxes, the mass transfer coefficient $k_{A I I}$ can be derived as follows:

- the flux during the clean water flux measurements is given by:

$J_{\mathrm{w}}=\Delta P /\left(\eta_{0} R_{\mathrm{m}}\right)$

- the flux during the experiment is given by:

$\mathrm{J}_{\mathrm{v}}=(\Delta \mathrm{P}-\Delta \Pi) /\left(\eta_{0} \mathrm{R}_{\mathrm{m}}\right)$

so that the osmotic pressure difference $\Delta \Pi$ can be written as:

$\Delta \Pi=\Delta P\left[1-\left(J_{\mathrm{v}} / J_{\mathrm{w}}\right)\right]$

If, from independent measurements, the relationship between the osmotic pressure and the concentration is known, resulting in a relationship described as in eqn. (14), the concentration at the membrane interface, $C_{\mathrm{m}}$, can be calculated. Then, using eqn. (12), or eqn. (18) when $\mathscr{R}_{\mathrm{obs}}=1$, the mass transfer coefficient $k_{i \Pi \Pi}$ can be derived easily.

Results obtained by other workers using the osmotic pressure method are given below. Apart from the flow conditions (laminar or turbulent, etc.), the test solute and the membrane, the magnitude of the experimental flux (or more specifically $J_{v} / v^{x}$ ) also seems to influence the comparison of "experimental" values of the mass transfer $k_{\Delta I}$ and the various "theoretical" values. Therefore the range of fluxes is also given when available.

(i) Goldsmith [11], using several Dextrans and PEG, found good agreements for both laminar and turbulent conditions [using eqn. (2) and (6)] after adapting the value of the diffusion coefficient to values of $D=5 \times 10^{-11}$ $\mathrm{m}^{2} / \mathrm{sec}$ for laminar conditions and $D=1-2 \times 10^{-11} \mathrm{~m}^{2} / \mathrm{sec}$ for turbulent conditions. If the normal value of the diffusion coefficient, i.e. $D \approx 6-8 \times 10^{-11} \mathrm{~m}^{2} /$ sec had been used, the resulting experimental value for $k_{A \Pi}$ would have been smaller than the theoretical values obtained from the equations derived by Grober and Harriot-Hamilton, respectively. The results clearly showed a dependence on the velocity, being $\sim v^{0.5}$ and $\sim v^{0.92}$ for the two different cases of flow conditions. The maximum flux obtained was $1.5 \times 10^{-5} \mathrm{~m} / \mathrm{sec}$ in the turbulent case and about $1.0 \times 10^{-5} \mathrm{~m} / \mathrm{sec}$ in the laminar case.

(ii) Trägårdh and Ölund [12] also obtained a smaller experimental mass transfer coefficient $k_{\Delta \Pi}$ than the theoretical values according to the ChiltonColburn equation [eqn. (4)] using Dextrans and several types of membrane, although in some cases there was a reasonable agreement. No flux data were given for the experiments. 
(iii) Jonsson [2] found, in experiments using Dextrans and a whey protein solution, that $k_{\Delta \Pi}$ is smaller (approximately $25 \%$ ) than the theoretical values according to eqns. (3) and (4) for laminar and turbulent flow conditions, respectively. A tendency for the mass transfer coefficient to increase with the velocity (with an exponent of 0.33 or 0.8 ) could be identified. For the calculation of the mass transfer coefficient during these experiments, identical relations were used for the osmotic pressure of Dextrans T10 and T20. The experimental fluxes, $J_{v}$ were $0.5-3 \times 10^{-5} \mathrm{~m} / \mathrm{sec}$, and they increased with increasing cross-flow velocities. The ratio $J_{v} / v$ was smaller than $2 \times 10^{-5}$.

(iv) Nakao et al. [6] showed that fluxes calculated with the osmotic pressure model and using a mass transfer coefficient according to the Leveque equation [laminar flow conditions, eqn. (3)] were nearly identical to the experimental fluxes, while in the turbulent region [using Deissler's equation, eqn. (5)] the calculated fluxes were overestimated. Apparently the actual mass transfer coefficient was much smaller than that given by Deissler's expression. Using a concentration-dependent viscosity and diffusivity, the experimental mass transfer coefficients could be estimated reasonably well.

(v) Wijmans [13] calculated mass transfer coefficients in the turbulent region over a large range of fluxes and $J_{\mathrm{v}} / v$ ratios. The experiments were performed using Dextrans at various concentrations and applied pressures. The experimentally determined osmotic pressures as a function of concentration showed an almost identical dependence on the concentration for Dextrans T70 and T500. The values of the experimental mass transfer coefficients $\left(k_{\Delta \Pi}\right)$ were compared with values obtained by using Deissler's equation $\left(k_{\mathrm{D}}\right)$. The ratio $k_{\Delta \Pi} / k_{\mathrm{D}}$ appeared to be highly dependent on the flux, and especially on the $J_{\mathrm{v}} / v$ ratio: $k_{\Delta \Pi} / k_{\mathrm{D}}$ increased with increasing $J_{\mathrm{v}} / v$. Starting from $k_{\Delta I} / k_{\mathrm{D}} \approx 0.6$, this value increased almost linearly to 1.1 ; the ratio was 1 at $J_{\mathrm{v}} / v \approx 2 \times 10^{5}$.

\section{The velocity variation method}

Using $\mathscr{R}_{\mathrm{obs}}-1-C_{\mathrm{p}} / C_{\mathrm{b}}$ for the observed retention and $\mathscr{R}=1-C_{\mathrm{p}} / C_{\mathrm{m}}$ for the intrinsic (or real) retention, the following relation can be derived from eqn. (12):

$$
\ln \left[\left(1-\mathscr{R}_{\text {obs }}\right) / \mathscr{R}_{\text {obs }}\right]=\ln [(1-\mathscr{R}) / \mathscr{R}]+J_{\mathrm{v}} / k
$$

The Sherwood relations for $k$, as given in the introductory section, always show dependence on the cross-flow velocity of the type $k=\mathrm{b} v^{\mathrm{a}}$, where $\langle a\rangle \approx 0.33$ for laminar conditions and $\langle a\rangle=0.75-0.91$ for turbulent conditions. Thus the equation for the retention can be written as:

$\ln \left[\left(1-\mathscr{R}_{\text {obs }}\right) / \mathscr{R}_{\text {obs }}\right]=\ln [(1-\mathscr{R}) / \mathscr{R}]+J_{\mathrm{v}} /\left(\mathrm{b} v^{\mathrm{a}}\right)$

By plotting the experimental values of $\ln \left[\left(1-\mathscr{R}_{\text {obs }}\right) / \mathscr{R}_{\text {obs }}\right]$ as a function of $J_{\mathrm{v}} / v^{\mathrm{a}}$, where the value of the exponent $\langle a\rangle$ should be chosen in advance, the intrinsic retention and the constant $b$ can be determined graphically. The re- 
lation for the mass transfer coefficient as a function of the various experimental variables can now be obtained by fitting the data found in the different experimental circumstances. A considerable disadvantage of this semi-empirical method is the necessity of an incomplete retention. While in practice for many solutes the retention is preferably complete $(=1)$, in this case the retention should be rather low.

Some results obtained by other researchers are:

(1) The observed retention is a function of many process variables $[11,12,14$ 18 ]: $\mathscr{R}_{\text {obs }}$ increases with increasing molecular weight, increasing cross-flow velocity and increasing concentration in the bulk, while $\mathscr{R}_{\text {obs }}$ also increases when a solute mix is used. $\mathscr{R}_{\text {obs }}$ first increases and then decreases again when the applied pressure is increased. The intrinsic retention $\mathscr{R}$ increases with increasing permeate flux, increasing applied pressure and higher molecular weights, but is constant at increasing cross-flow velocities.

(2) Nakao and Kimura [18] used PEG $4000\left(M_{\mathrm{w}}=3000\right)$, vitamin $\mathrm{B}_{12}$ $(M . W .=1355)$, raffinose $(M . W .=504)$, sucrose $(M . W .=342)$, glucose $(M . W .=180)$ and glycerol (M.W. =92) during their experiments. In turbulent conditions, the experimentally determined mass transfer coefficients seemed to fit excellently (graphically) with Deissler's equation [eqn. (5)], but appeared to deviate by up to $40 \%$ numerically. The general tendency, however, was to follow Deissler's equation.

(3) Jonsson and Boesen [19] calculated the mass transfer coefficient, as derived from reverse osmosis experiments with $\mathrm{NaCl}, \mathrm{CaCl}_{2}$ and $\mathrm{MgSO}_{4}$, for laminar and turbulent conditions. For the turbulent case, an exponent of value $\langle a\rangle=0.80$ was used and this resulted in $k$ values which were equal to or only a little larger than the $k$ values calculated according to the Chilton-Colburn relation [eqn. (4) ]. However, when the flux increased appreciably, distinct deviation from the straight line could be observed ( $\langle a\rangle$ smaller than 0.80 ). Under laminar conditions the values of the mass transfer coefficients were scattered more or less around the line for the "theoretical" mass transfer coefficient given by the Graetz-Leveque equation [eqn. (3)]. This depended on the Reynolds number: at low Reynolds numbers the values of the exponent $\langle a\rangle$ was around 0.33 (up to $R e \approx 700$ ), but this value increased with increasing Re.

(4) Nakao et al. [20] used high flux membranes or high temperatures to study the effect of high fluxes, again using solutes of low molecular weight. When the high flux was obtained by the use of a high flux membrane the agreement between the mass transfer coefficients $k_{\mathrm{D}}$ calculated from Deissler's equation and those calculated according to the velocity variation method $\left(k_{\mathrm{vv}}\right)$ was highly dependent on the $J_{\mathrm{v}} / k_{\mathrm{D}}$ ratio: at low $J_{\mathrm{v}} / k_{\mathrm{D}}$ ratios (up to 0.5 ) the $k_{\mathrm{vv}} / k_{\mathrm{D}}$ ratio was approximately equal to one, while at higher $J_{\mathrm{v}} / k_{\mathrm{D}}$ ratios the $k_{\mathrm{vv}} / k_{\mathrm{D}}$ ratio increased. This increase appeared to fit the Stewart correction for high mass transfer very well. When the high flux was obtained by the use of 
high temperatures (thus increasing the diffusivity and decreasing the viscosity, using $\eta_{\mathrm{o}} D / T=$ constant), the $k_{\mathrm{vv}}$ values matched the $k_{\mathrm{D}}$ values closely.

\section{Experimental}

Ultrafiltration experiments were performed in three different cross-flow ultrafiltration systems:

System $A$, a membrane system with four tubular membranes in series (Fig. 2), $d_{\mathrm{h}}=1.45 \times 10^{-2} \mathrm{~m}$, the permeate being collected for each membrane separately;

System $B$, a system with a (rectangular) thin channel module in which different types of flat membranes were used (Fig. 3), $d_{\mathrm{h}}=1.09 \times 10^{-2} \mathrm{~m}$, the permeate being collected from each membrane separately, and

System $C$, a DDS Mini-Lab 10 system in which four flat membranes were used (Fig. 4), $d_{\mathrm{h}}=1.5 \times 10^{-3} \mathrm{~m}$ (average). The support plates had four channels with the characteristic geometry of DDS flat membrane cells. Because of the small hydraulic diameter the pressure drop over the module was rather

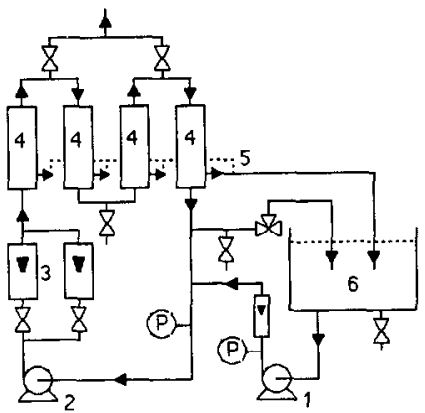

Fig. 2. Schematic representation of the tubular membrane ultrafiltration equipment (system A). 1: injection pump; 2: recirculation pump; 3 : flowmeters; 4 : membrane modules; 5 : permeate drain; 6: bulk solution tank.

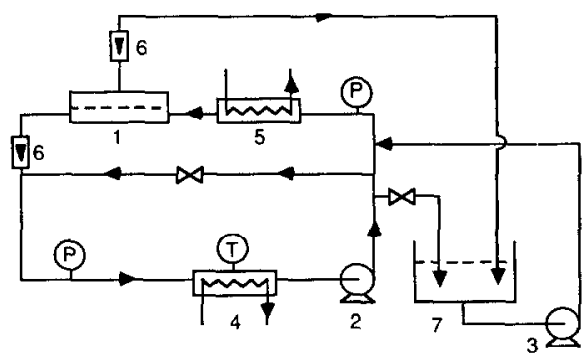

Fig. 3. Schematic representation of the thin channel ultrafiltration equipment (system B). 1: membrane module; 2: recirculation pump; 3: injection pump; 4: heat exchanger with thermistor; 5: heat exchanger; 6 : flowmeters; 7 : bulk solution tank. 


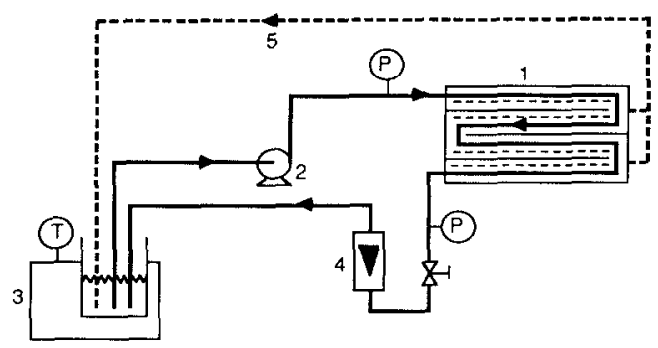

Fig. 4. Schematic representation of system $C$ with the DDS Mini-Lab 10 module. 1: membrane module; 2: recirculation pump; 3 : bulk solution in thermostat bath; 4 : flowmeter; 5 : permeate drain.

large (up to $1.5 \times 10^{5} \mathrm{~Pa}$ at $v=1.88 \mathrm{~m} / \mathrm{sec}$ ); the permeate was collected from two membranes together, while the flux was calculated using the (measured) average pressure drop.

The total membrane areas in the different modules were $222 \times 10^{-4} \mathrm{~m}^{2}$, two membranes of about $36 \times 10^{-4} \mathrm{~m}^{2}$ each (variable), and $336 \times 10^{-4} \mathrm{~m}^{2}$, respectively. The amount of bulk solution was rather different from the three systems, being 10,20 and 21 , respectively.

The solutions used were Dextrans T10, T70 and T500 $\left(M_{\mathrm{w}}=10,500,72,200\right.$ and 465,000 , respectively) in demineralized water, which was treated by ultrafiltration and reverse osmosis before use, and solutions of the protein bovine serum albumin (BSA, M.W. $=69,000$ ) in a phosphate buffer at pH 7.4 with 0.1 $N \mathrm{NaCl}$ added, to give a solution with ionic strength $I=0.125 \mathrm{~N}$. The concentration in the Dextran concentrate and permeate solutions was determined by a Beckman Model 915A Total Organic Carbon analyzer. The concentrations in the BSA solutions were determined using a Waters HPLC system.

The equation used for the dependence of the osmotic pressure on the concentration was identical for the three dextran solutions, which is valid at higher concentrations at which the molecular weight is of minor importance [1,2]; it was:

$\Delta \Pi_{\text {dextrans }}=37.5 C+0.752 C^{2}+7.64 \times 10^{-3} C^{3}$

For BSA this dependence was calculated as:

$$
\begin{aligned}
\Delta \Pi_{\mathrm{BSA}}= & (R T / M)\left[C-1.09 \times 10^{-2} C^{2}+1.24 \times 10^{-4} C^{3}\right. \\
& \left.+\left(C^{2}+4.576 \times 10^{5}\right)^{0.5}-1.38 \times 10^{4}\right]
\end{aligned}
$$

The latter equation was developed according to Vilker et al., taking into account the excluded volume (first term) and the Donnan effects (second term) [21]. The values of the parameters needed for this calculation can be found in Ref. [21] (see also Ref. [22]).

The tubular membranes (obtained from Wafilin B.V., Hardenberg, The Netherlands) used in system A were WFS-5010 and WFS-6010 (polysulfone), 
WFE-X005 and WFE-X006 [poly (ether sulfone)] and WFA-3010 and WFA4010 (polyacrylonitrile), all having a 99\% + observed retention for the solutes studied (Dextran T70 and BSA). The membranes used in system B were Kalle Nadir 47, Nadir 66 and P.S. 50 (polysulfone) having $99 \%+, 90 \%+$ and $65 \%+$ observed retention, respectively, for Dextran T70 and $99 \%+$ for BSA. The membranes used in the DDS Mini-Lab 10 (system C) were CA600PP (cellulose acetate) having a 99\% + observed retention for Dextran T70 and T500 and for BSA; for Dextran T10 the observed retention was smaller and varied with the experimental conditions.

The flow conditions were different for the various systems. They were considered to be: for system $A$, turbulent ( $R e=14,400 v$, varying from 14,400 to $43,200$ depending on $v)$; for system $\mathrm{B}$, turbulent ( $R e=10,900 v$, minimally 3270 to 15,260$)$; and for system C, laminar ( $R e=1500 v$, which is $R e=765$ to a maximum of 2820). Although the lower limit of the Reynolds numbers in system $\mathrm{B}$ and the upper limit in system $\mathrm{C}$ can be expected to fall in the transition region of the laminar and turbulent flow regime, for reasons of convenience they will be treated as being turbulent and laminar, respectively. The comparison of the influence of the flow conditions in one system will then be more realistic as well.

The temperature was $25^{\circ} \mathrm{C}$ during the experiments performed in systems $\mathrm{B}$ and $C$; the temperature of the bulk solution varied when system $A$ was used. In the latter case the appropriate correction for variations in viscosity was applied.

When using various solutes and membranes, flux reduction as a result of adsorption and pore blocking is very common, especially when proteins and hydrophobic membranes are involved. For that reason, the flux decline due to concentration polarization of protein solutions filtered through a hydrophobic membrane was calculated from the actual flux and the clean water flux measured after the experiments were performed. When Dextrans were involved, or when cellulose acetate membranes were used, the flux decline was usually very small, and no significant difference in results was found whether the clean water flux before or after the ultrafiltration experiment was used.

\section{Results}

In this section the results from the method using the osmotic pressure difference will be given first. General tendencies will be shown, as well as the influence of the various experimental circumstances on the calculated mass transfer coefficient. The results from the velocity variation method will then be presented, after which these two methods will be compared mutually. The plots given in this section will represent typical results taken from many ultrafiltration experiments with Dextrans or BSA in the three different systems.

A typical result of a set of ultrafiltration experiments, with Dextran T70 as the solute, is given in Fig. 5. 


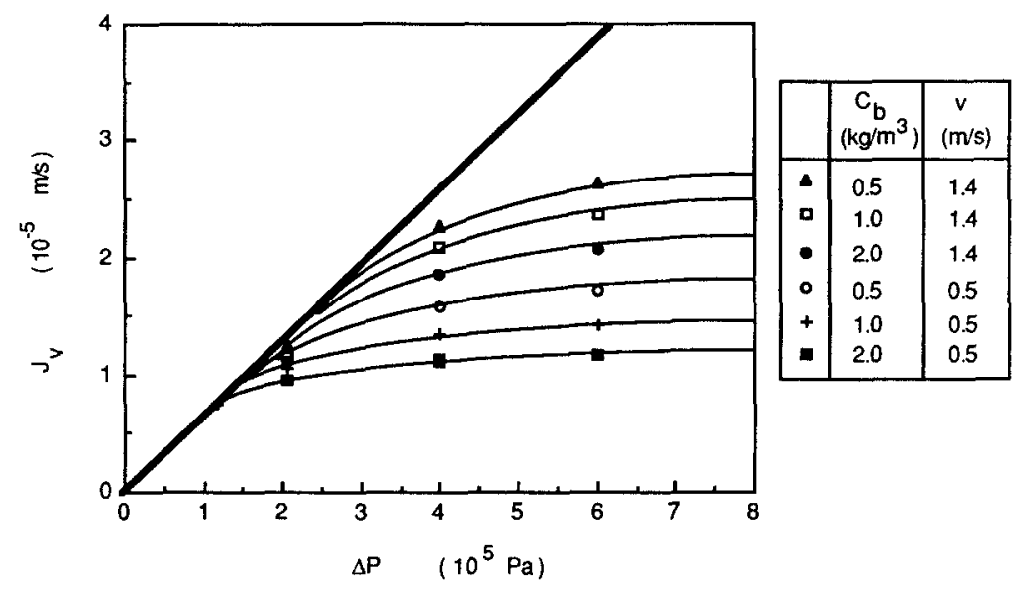

Fig. 5. Permeate flux as a function of the bulk concentration and the cross-flow velocity. The straight line represents the clean water flux. Experiments performed in ultrafiltration system B, with Dextran T70 as the solute.

The permeate flux $J_{v}$ increases with increasing pressure, although not linearly. Beyond a certain applied pressure, and depending on the concentration in the bulk solution and the cross-flow velocity, the flux will reach the so-called limiting flux region, where an increase of the applied pressure will not lead to a further increase of the permeate flux. In Fig. 5 it can be seen that the flux decreases with increasing concentration in the bulk and with decreasing crossflow velocity. The limiting flux region is nearly reached in the case of $C_{\mathrm{b}}=2.0$ $\mathrm{kg} / \mathrm{m}^{3}$ and $v=0.5 \mathrm{~m} / \mathrm{sec}$ beyond $\Delta P=4.0 \times 10^{5} \mathrm{~Pa}$.

\section{A. The osmotic pressure method}

When the fluxes during ultrafiltration of a solution are known, they can be compared to the "clean water flux" at equal applied pressures, and by using eqn. (20) the osmotic pressure difference across the membrane can be calculated. With the help of the relations for the osmotic pressure as a function of the concentration, the concentration at the membrane wall is obtained. Then, using the value of the concentration in the bulk, the mass transfer coefficient $k_{\Delta I}$ can be calculated from eqn. (18).

Although in the literature the values of the (experimental, or rather semiempirical) mass transfer coefficients are mostly compared with coefficients calculated from Deissler's equation [ $k_{\mathrm{D}}$, eqn. (5) ], for solutes such as BSA and Dextrans $(S c \approx 13,000-22,000)$ mass transfer coefficients calculated from the Sherwood relation of Harriott and Hamilton [ $k_{\mathrm{HH}}$; eqn. (6)] should be used. In Figs. 6-9, and in Figs. 11 and 12, the calculated experimental coefficients $k_{\Delta I I}$ will be compared with $k_{\mathrm{HH}}$, studying the influence of the different process 


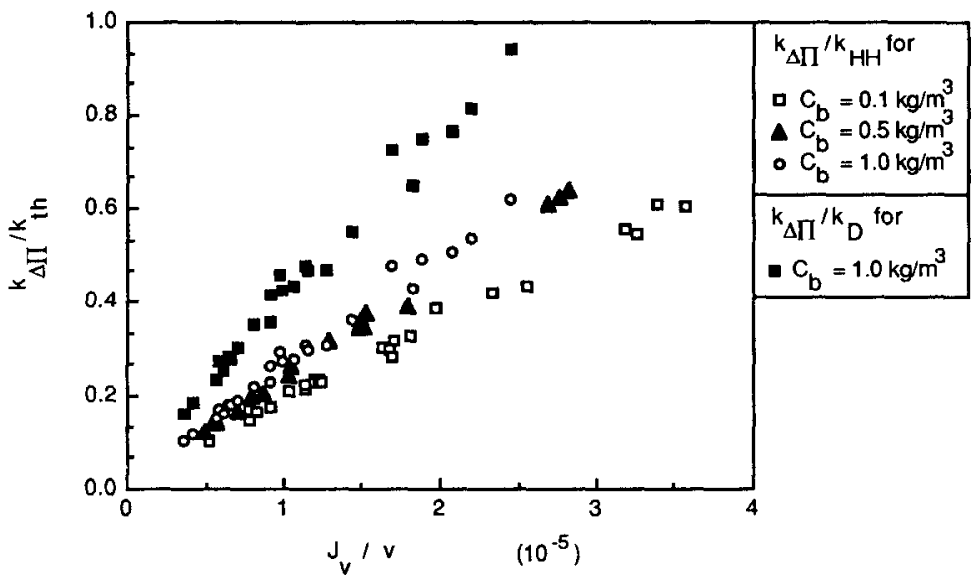

Fig. 6. Comparison of the mass transfer coefficient $k_{\Delta I}$ obtained from experiments with the mass transfer coefficient according to Harriott-Hamilton, $k_{\mathrm{HH}}$, for three different bulk concentrations and one comparison with the mass transfer coefficient according to Deissler, $k_{\mathrm{D}}$. Experiments were performed with BSA at $\mathrm{pH} 7.4$ in ultrafiltration system A.

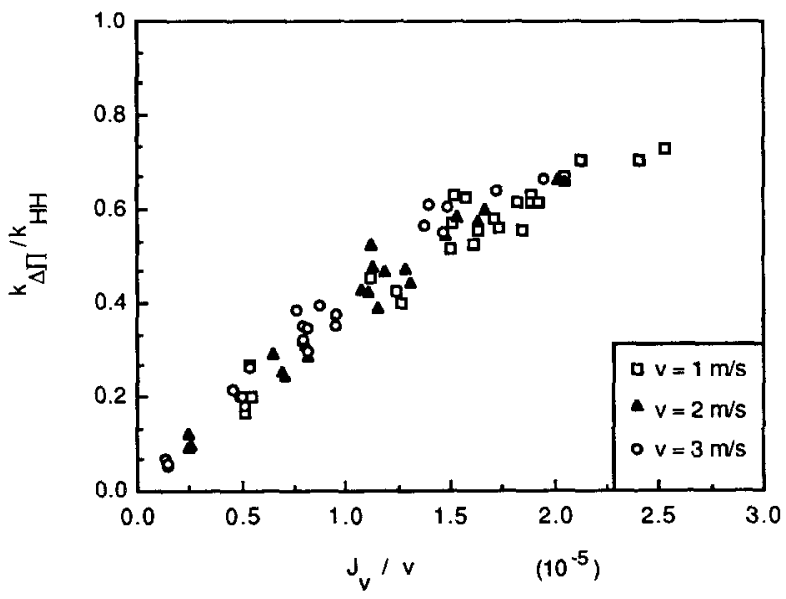

Fig. 7. The $k_{\Delta \Pi} / k_{\mathrm{HH}}$ ratio as a function of the $J_{\mathrm{v}} / v$ ratio, at three different cross-flow velocities. Experiments performed with Dextran T70 in ultrafiltration system A.

parameters. The varying experimental parameter will be the frequently used $J_{\mathrm{v}} / v$ ratio.

In Fig. 6 the $k_{\Delta \Pi} / k_{\mathrm{HH}}$ ratio is given for three different bulk concentrations $C_{\mathrm{b}}\left(0.1,0.5\right.$ and $\left.1.0 \mathrm{~kg} / \mathrm{m}^{3}\right)$; both $v$ and $\Delta P$ were also varied, resulting in a different dependence on the $J_{\mathrm{v}} / v$ ratio. The $k$ ratio dependence on $J_{\mathrm{v}} / v$ seems to be almost linear, and the slope of the line for $C_{\mathrm{b}}=0.1 \mathrm{~kg} / \mathrm{m}^{3}$ is clearly smaller than the slopes of the lines for $C_{\mathrm{b}}=0.5$ and $1.0 \mathrm{~kg} / \mathrm{m}^{3}$. The difference in slope between 0.5 and $1.0 \mathrm{~kg} / \mathrm{m}^{3}$ is much smaller. Although the $k_{\Delta \Pi} / k_{\mathrm{HH}}$ ratio tends 


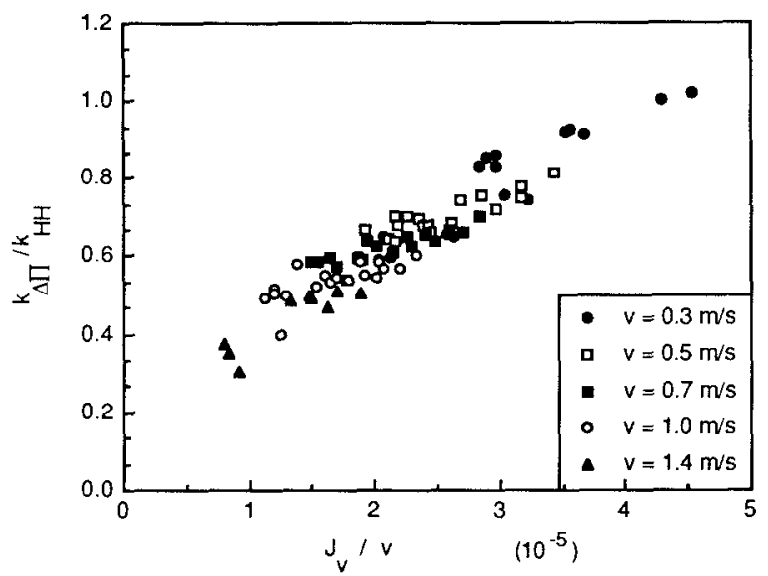

Fig. 8. The $k_{A I} / k_{\mathrm{HH}}$ ratio as a function of the $J_{v} / v$ ratio, at five different cross-flow velocities. Experiments performed with Dextran T70 in ultrafiltration system B.

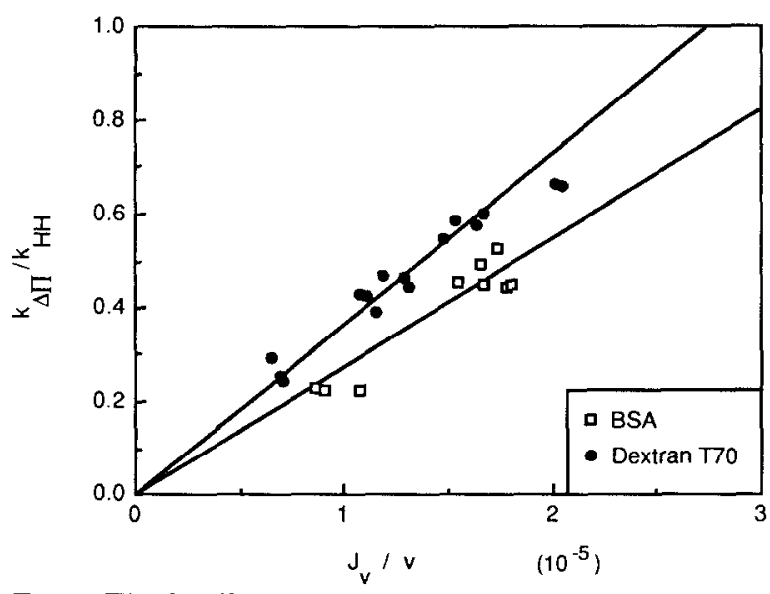

Fig. 9. The $k_{A I} / k_{\mathrm{HH}}$ ratio as a function of the $J_{\mathrm{v}} / v$ ratio for different solutes. The experiments were performed with BSA and Dextran T70 in ultrafiltration system A, at $v=2 \mathrm{~m} / \mathrm{sec}$ (turbulent conditions) and $C_{\mathrm{b}}=1 \mathrm{~kg} / \mathrm{m}^{3}$.

to be larger for $C_{\mathrm{b}}=1.0 \mathrm{~kg} / \mathrm{m}^{3}$ than for $0.5 \mathrm{~kg} / \mathrm{m}^{3}$ this trend is perhaps not significant, owing to the experimental error (ca. 10\%) and the resulting error in the $k$ ratio. Because of this dependence on the concentration, the other parameters will be studied using concentrations of $0.5,1.0$ and $2.0 \mathrm{~kg} / \mathrm{m}^{3}$ only. In Fig. 6 the $k_{\Delta \Pi} / k_{\mathrm{D}}$ ratio is also given for comparison. This ratio is about 1.5 times larger than the $k_{\Delta \Pi} / k_{\mathrm{HH}}$ ratio, a difference caused for the most part by the smaller exponent of the Schmidt number of Deissler's equation.

In Figs. 7 and 8 the influence of the cross-flow velocity is represented, using $C_{\mathrm{b}}=0.5,1.0$ and $2.0 \mathrm{~kg} / \mathrm{m}^{3}$. In Fig. 7 the $k_{\Delta n} / \mathrm{HH}$ ratio is plotted as a function of the $J_{\mathrm{v}} / v$ ratio for experiments performed with Dextran T70 in system A, 


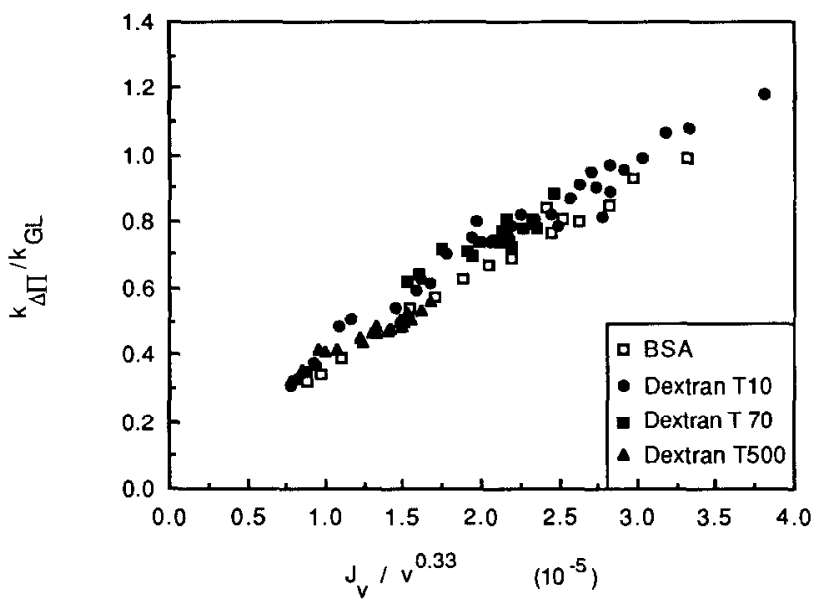

Fig. 10. The $k_{\Delta \Pi} / k_{\mathrm{GL}}$ ratio as a function of the $J_{\mathrm{v}} / v^{0.33}$ ratio, for different solutes. The experiments were performed with BSA and Dextran T10, T70 and T500 in ultrafiltration system $\mathrm{C}$, at various cross-flow velocities and $C_{\mathrm{b}}=1 \mathrm{~kg} / \mathrm{m}^{3}$.

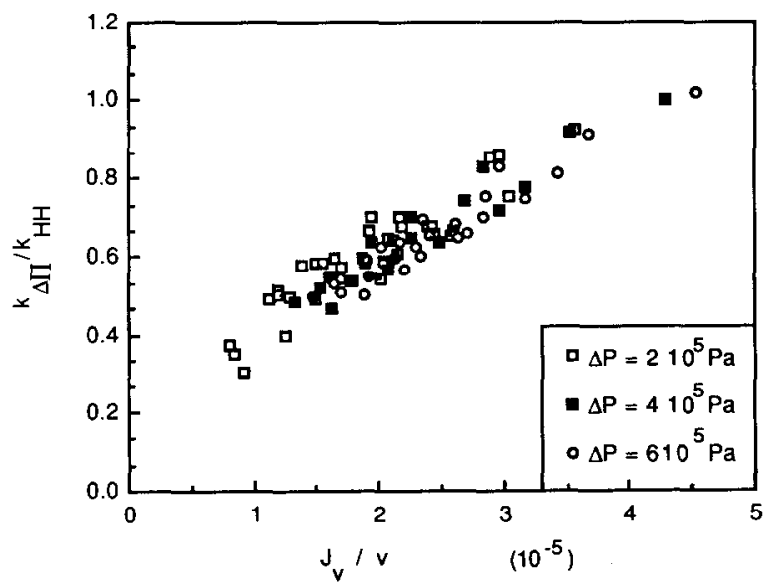

Fig. 11. The $k_{\Delta \Pi} / k_{\mathrm{HH}}$ ratio as a function of the $J_{\mathrm{v}} / v$ ratio, at three different applied pressures. Experiments performed with Dextran T70 in ultrafiltration system B.

while in Fig. 8 the results of experiments with Dextran T70 in system B are represented. From the data in both Fig. 7 and Fig. 8 it can be concluded that there is no difference in results when the velocity is varied. For all velocities equal trends can be observed: the $k_{A \Pi} / k_{\mathrm{HH}}$ ratio increases with increasing $J_{\mathrm{v}} /$ $v$ ratio. All data together show that the increase is almost linear.

When two different solutes are studied in the same ultrafiltration system, there are two essentially different physico-chemical parameters: the osmotic pressure as a function of concentration and the (bulk) diffusion coefficient. In Fig. 9 the results of ultrafiltration experiments in system A with BSA and 


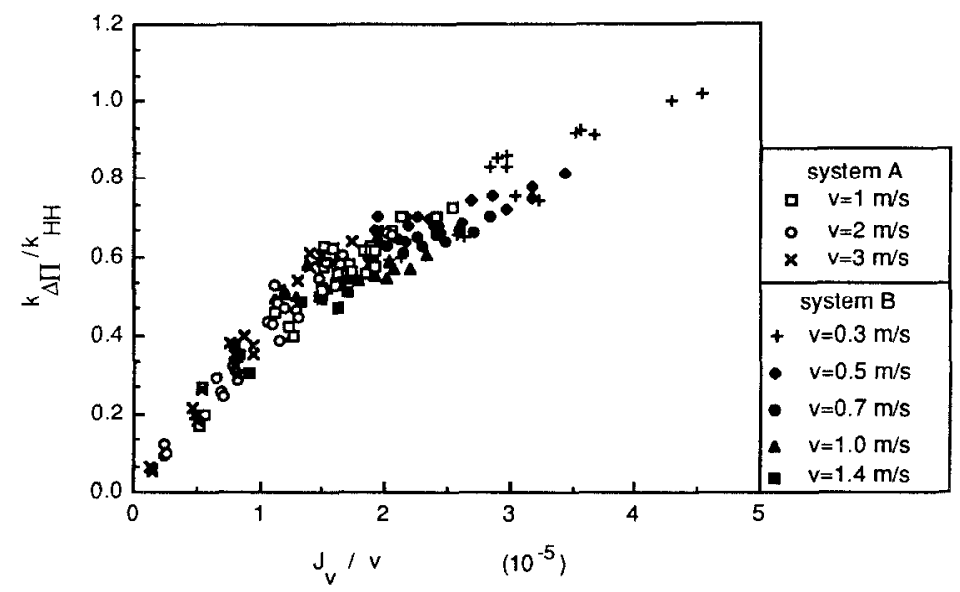

Fig. 12. The $k_{A \Pi} / k_{\mathrm{HH}}$ ratio as a function of the $J_{\mathrm{v}} / v$ ratio at different cross-flow velocities in two ultrafiltration systems: system A with $d_{\mathrm{h}}=1.45 \times{ }^{\circ} 0^{-3} \mathrm{~m}$ and system B with $d_{\mathrm{h}}=1.09 \times 10^{-2} \mathrm{~m}$. The experiments were performed with Dextran T 70 at $C_{\mathrm{b}}=1.0 \mathrm{~kg} / \mathrm{m}^{3}$.

Dextran T70 are given. Despite the limited number of data points and the scatter in the data, the results show that there is a difference between the two solutes when filtered at the same bulk concentration in the same system. The mass transfer coefficient ratio $k_{\Delta n} / k_{\mathrm{HH}}$ for BSA is some $20 \%$ smaller than for Dextran T70. This same conclusion can be drawn when other concentrations and velocities are studied.

In Fig. 10 this comparison is made for BSA versus three different Dextrans, but in a totally different ultrafiltration system (system $C$ ) and at laminar flow conditions. The $k_{\Delta \Pi} / k_{\mathrm{GL}}$ ratio seems to be smaller again for BSA than for the Dextrans, although the difference is not as large as in the case of turbulent flow conditions.

In Fig. 11 the results of experiments performed at different applied pressures, with one solute (Dextran T70) in one ultrafiltration system (B), are compared. No systematic difference can be observed between the data points of $\Delta P=4.0 \times 10^{5} \mathrm{~Pa}$ and $\Delta P=6.0 \times 10^{5} \mathrm{~Pa}$, while for the data obtained at $\Delta P=2.0 \times 10^{5} \mathrm{~Pa}$ the $k_{\Delta I I} / k_{\mathrm{HH}}$ ratio is slightly larger at equal $J_{\mathrm{v}} / v$ ratios.

Another important variable is the hydraulic diameter $d_{\mathrm{h}}$ of the membrane filtration system. Although the dependence of the mass transfer coefficient on $d_{\mathrm{h}}$ is only $\left(d_{\mathrm{h}}\right)^{0.09}$ in Harriott-Hamilton's Sherwood relation, $d_{\mathrm{h}}$ determines the Reynolds number (for one solute, together with the cross-flow velocity) and thus the laminar-turbulent transition region. In Fig. 12 a comparison is made between the ultrafiltration systems $A$ and $B$ with hydraulic diameters of $1.45 \times 10^{-2} \mathrm{~m}$ and $1.09 \times 10^{-2} \mathrm{~m}$, respectively. From the data points in Fig. 12, which overlap closely for the two systems, it can be concluded that the mass 
transfer coefficient ratio is not significantly dependent on the system or its difference in hydraulic diameter.

Further remarks on the experimental results can be found in the discussion section.

\section{B. The velocity variation method}

As shown in the theoretical section, the experimental data needed for a typical plot in the velocity variation method are the observed retention $\mathscr{R}_{\text {obs }}$, the flux $J_{\mathrm{v}}$ and the cross-flow velocity $v$. After choosing the exponent $\langle a\rangle$ of the cross-flow velocity (in $k=b v^{a}$, which depends on laminar or turbulent conditions), the main variable for a certain combination of solute and membrane appears to be the applied pressure.

In Fig. 13 a typical example is given. The lines fitting the data points all show the same slope, which is $1 / b$ in $k=b v^{a}$. This was imposed because equal slopes are expected when the applied pressure is the only variable and, more important, when a fit is made at each pressure separately the difference in slopes can be very large (in this case up to $35 \%$ ); the extrapolation of $J_{\mathrm{v}} / v^{0.33}=0$, to obtain the values of the intrinsic retention at the various pressures would then give nearly random values. Now the intrinsic retentions vary from $\mathscr{R}=0.975$ at $\Delta P=1.0 \times 10^{5} \mathrm{~Pa}$, via $\mathscr{R}=0.989$ and $\mathscr{R}=0.994$, to $\mathscr{R}=0.997$ at $\Delta P=4.0 \times 10^{5} \mathrm{~Pa}$.

Improvement of these results is hard to achieve, as a certain combination of solute and membrane only gives a limited range of fluxes and observed retentions. Duplicate measurements, given in Fig. 14, show the same trends, al-

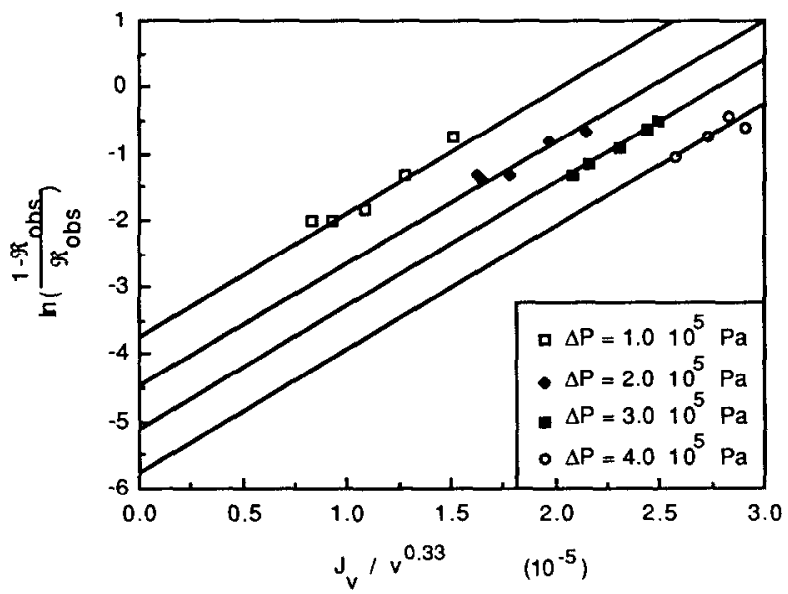

Fig. 13. The typical "velocity variation plot" for laminar conditions, $\ln \left[\left(1-\mathscr{R}_{\text {obs }}\right) / \mathscr{R}_{\text {obs }}\right]$ as a function of $J_{\mathrm{v}} / v^{0.33}$. Dextran T10 was used in ultrafiltration system C using a CA600PP membrane, $C_{\mathrm{b}}=1.0 \mathrm{~kg} / \mathrm{m}^{3}$. 
though for some data points a deviation can be observed (the two lowest velocities at each pressure).

It will be clear that the derived semi-empirical mass transfer coefficient $k_{\mathrm{vv}}$ (for one solute) will have the same dependence on the velocity as the theoretical relations, because all slopes in the $\ln \left[\left(1-\mathscr{R}_{\text {obs }}\right) / \mathscr{R}_{\text {obs }}\right]$ versus $J_{\mathrm{v}} / v^{0.33}$ plot are equal. When the ratio $k_{\mathrm{vv}} / k$ (theoretical), where the relation of GraetzLeveque is used $\left(\sim v^{0.33}\right)$, is calculated, this results in a constant ratio $k_{\mathrm{vv}} / k_{\mathrm{GL}}$.

The range for choosing the exponent $\langle a\rangle$ for the cross-flow velocity is fairly wide, as can be seen from Fig. 15, in which $v^{0.50}$ is used instead of $v^{0.33}$. This is a realistic exponent as well, as it can be found in Grober's Sherwood relation [eqn. (2)]. When the scattering data are compared to the more linear fits for data in Fig. 13, it must be concluded that the exponent $\langle a\rangle$ should be 0.33 instead of 0.50 , and this conclusion also holds when plots with equal scales are compared. The difference in scattering is not very large, however, when the data from Fig. 15 are compared with the combined sets of data represented in Fig. 14 (duplicate measurements). The problem of choosing the right exponent $\langle a\rangle$ still exists.

As described above, the curves of these experimentally determined mass transfer coefficients $k_{\mathrm{vv}}$, or their ratio to $k_{\mathrm{GL}}$ (the Graetz-Leveque relation for laminar flow conditions ), as a function of $J_{\mathrm{v}} / v^{0.33}$ will show a completely different picture from the $k_{A \Pi} / k_{\mathrm{GL}}$ ratio. In Fig. 16 the $k_{\mathrm{vv}} / k_{\mathrm{GL}}$ and $k_{\mathrm{vv}} / k_{\mathrm{Gr}}$ ratios

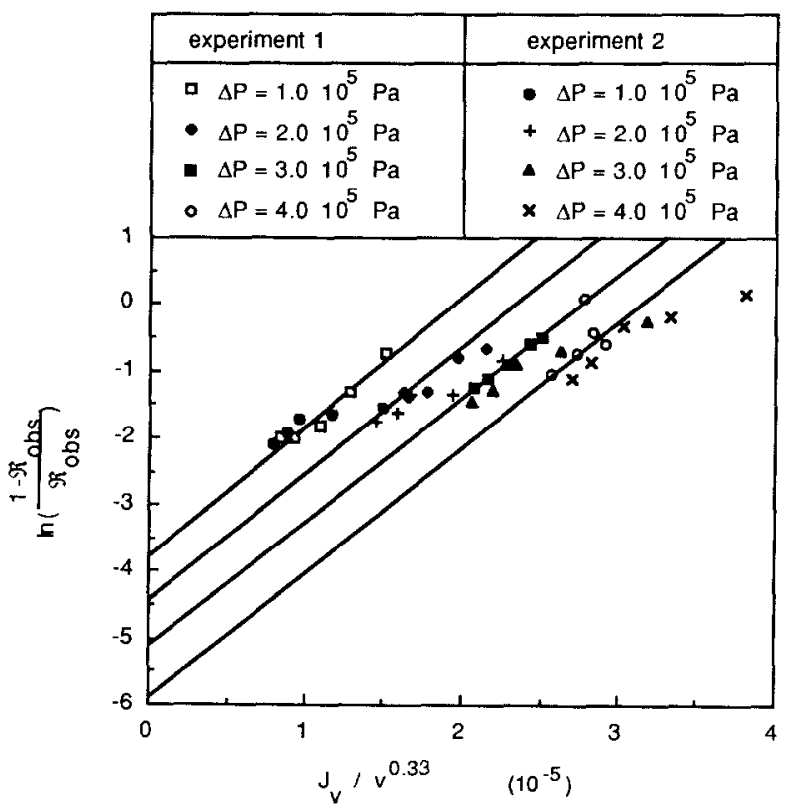

Fig. 14. A "velocity variation plot" for laminar conditions. A duplicate measurement in which Dextran T10 was used in ultrafiltration system C using a CA600PP membrane, $C_{\mathrm{b}}=1.0 \mathrm{~kg} / \mathrm{m}^{3}$. 


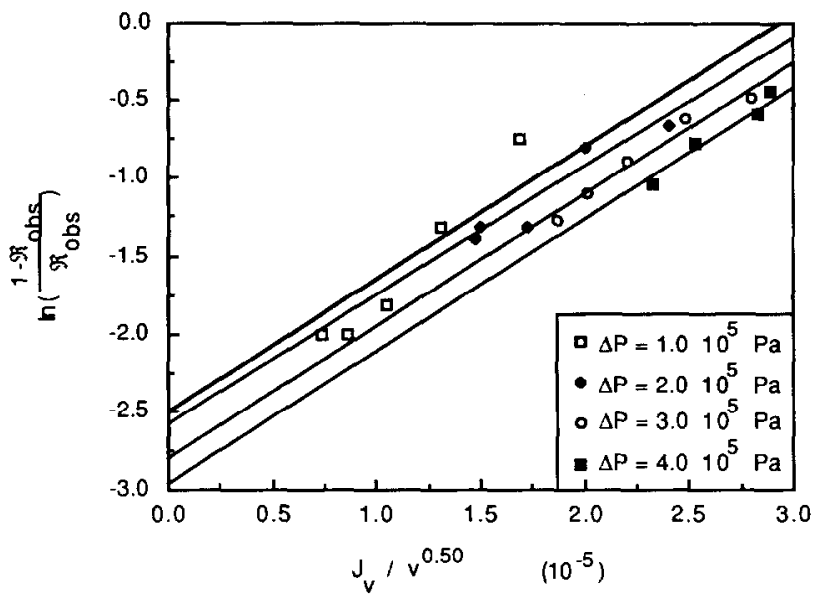

Fig. 15. The "velocity variation plot" for laminar conditions, now plotted as $\ln \left[\left(1-\mathscr{R}_{\text {obs }}\right) / \mathscr{R}_{\text {obs }}\right]$ vs. $J_{\mathrm{v}} / v^{0.50}$. Dextran T10 was used in ultrafiltration system C using a CA600PP membrane.

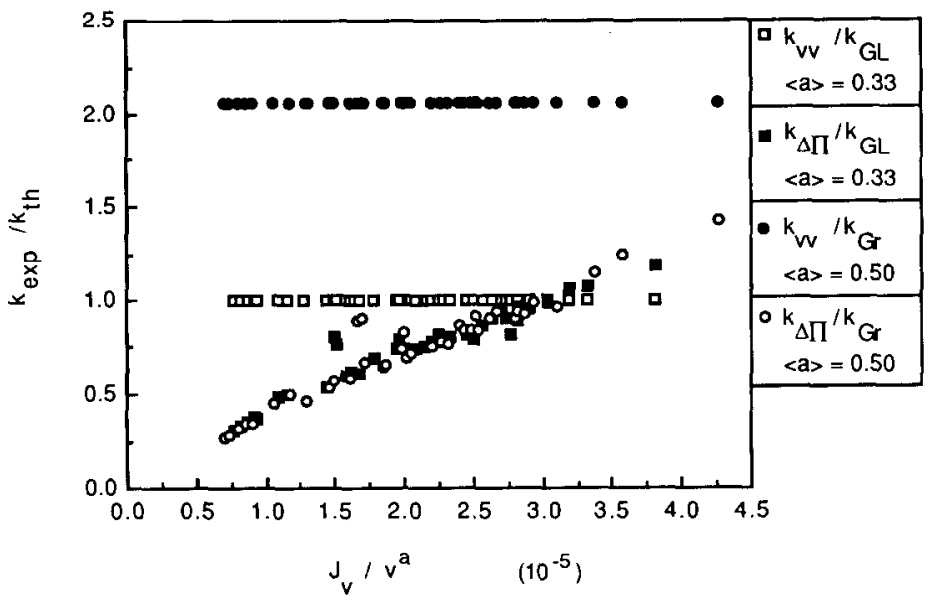

Fig. 16. Comparison of experimentally determined mass transfer coefficients according to the velocity variation method (using $v^{0.33}$ and $v^{0.50}$ ) and the osmotic pressure method, with mass transfer coefficients calculated from the Graetz-Leveque equation and Grober's equation, respectively. Dextran T10 was used in ultrafiltration system $\mathrm{C}$ using CA600PP membranes, $C_{\mathrm{b}}=1.0 \mathrm{~kg} /$ $\mathrm{m}^{3}$.

are given for the duplicate measurements mentioned above. The mass transfer coefficients according to both the velocity variation method (also using $v^{0.50}$ ) and the osmotic pressure method are calculated and compared with the mass transfer coefficient according to Graetz-Leveque $\left[\sim v^{0.33}\right.$, eqn. (3) $]$ and Grober $\left[\sim v^{0.50}\right.$, eqn. (2)].

The large difference between the two sets of results will be evident: while the 


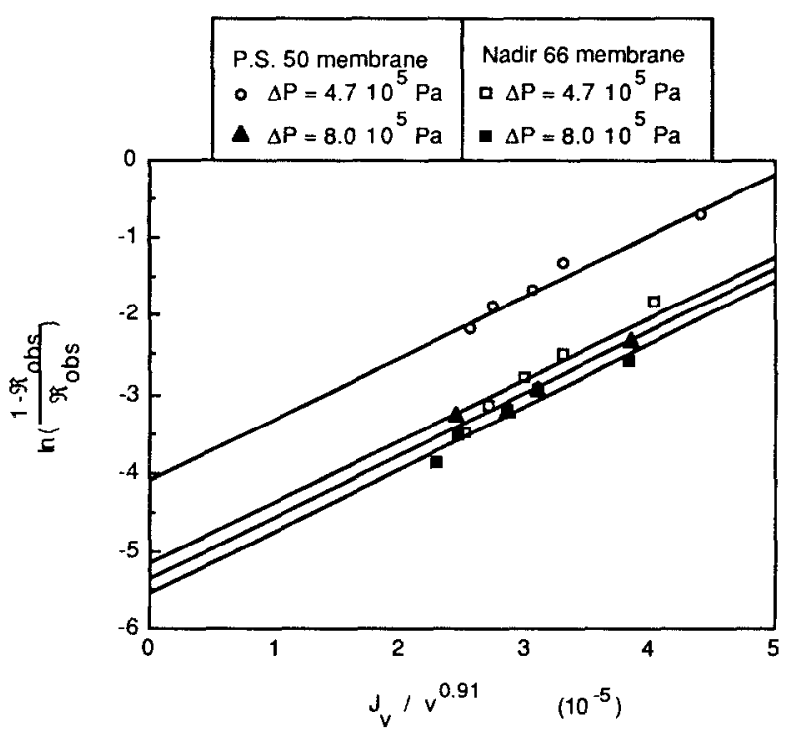

Fig. 17. The velocity variation plot for turbulent conditions. Dextran T70 was used in ultrafiltration system B with Nadir 66 and P.S. 50 membranes, $C_{\mathrm{b}}=0.5 \mathrm{~kg} / \mathrm{m}^{3} . \Delta P$ was $(4.7$ or 8.0$) \times 10^{5}$ $\mathrm{Pa}$.

osmotic pressure method results in mass transfer coefficient ratios which are more or less linear to the variable $J_{\mathrm{v}} / v^{0.33}$, the velocity variation method shows a constant ratio. When the $k_{\mathrm{vv}} / k_{\mathrm{GL}}$ ratio is compared for $v^{0.33}$ and $v^{0.50}$ a large difference is found: the ratio is about 1.0 when $v^{\mathrm{a}}$ is taken as $v^{0.33}$ and about 2.1 for $v^{0.50}$.

When the velocity variation method is used for turbulent flow conditions, the plots obtained can show the same trends: in Fig. 17 the experimental results for ultrafiltration of Dextran T70, using two different membranes at two applied pressures, are represented. Since the experimental conditions were turbulent, the exponent $\langle a\rangle$ in $J_{v} / v^{a}$ can be expected to be 0.91 , according to the Harriott-Hamilton relation [eqn. (6) ].

Again distinct sets of data can be found for each applied pressure and each membrane, indicating that the velocity variation method is much more responsive to experimental differences than the osmotic pressure method. Although the data given here show a reasonably linear and consistent behaviour with changing experimental circumstances, in practice a deviating behaviour can sometimes be observed, which will necessitate extending the series of experiments.

\section{Discussion}

\section{Osmotic pressure method}

In general, the results of the osmotic pressure method to determine mass transfer coefficients show somewhat scattered data. For some experimental 
circumstances, clear changes in the value of the mass transfer coefficient ratio can be observed, e.g., when the concentration in the bulk solution is very low (Fig. 6) or when the applied pressure is fairly low (Fig. 11). In the latter case it can be concluded that the mass transfer coefficient ratio appears to be relatively large when the flux reduction due to concentration polarization is not very large, i.e., when the limiting flux region is not reached at all. The influence of the other process variables (the cross-flow velocity and the hydraulic diameter) is found not to be significantly different from the $1 / v^{a}$ dependence. Furthermore, the results seem to be dependent on the type of solute used, which probably stems from the values of the physico-chemical parameters used in the calculations. For instance, for the diffusion coefficient of BSA a value of $6.9 \times 10^{-11} \mathrm{~m}^{2} / \mathrm{sec}$ was used, while in the literature many other values can be found (for a review see Ref. [23]), varying from 6 to $9 \times 10^{-11} \mathrm{~m}^{2} / \mathrm{sec}$. For the diffusion coefficient of Dextrans, a value of $6.0 \times 10^{-11} \mathrm{~m}^{2} / \mathrm{sec}$ was used, which is intermediate between the values of the coefficient at low concentrations (ca. $4 \times 10^{-11} \mathrm{~m}^{2} / \mathrm{sec}$ ) and at high concentrations (ca. $8 \times 10^{-11} \mathrm{~m}^{2} / \mathrm{sec}$ ) [1]. Adaptation of the calculated mass transfer coefficient ratios $k_{\Delta \Pi} / k_{\mathrm{HH}}$ and $k_{\Delta \Pi} /$ $k_{\mathrm{GL}}$, e.g., using a value of $8.0 \times 10^{-11} \mathrm{~m}^{2} / \mathrm{sec}$, would result in a close overlap of the two sets of data.

The fact that the cross-flow velocity seems to have no influence on the general course of dependence of $k_{\Delta I I} / k_{\mathrm{HII}}$ or $k_{\Delta \Pi} / k_{\mathrm{GL}}$ on $\mathrm{J} / \mathrm{v}^{a}$ (Figs. 7 and 8 ) implies that the correct exponent $\langle a\rangle$ of the cross-flow velocity has been used. However, when for instance in case of turbulent conditions an exponent 0.8 or 0.9 is used, hardly any difference can be observed. In Fig. 18 this is illustrated using $\langle a\rangle=0.8,0.9$ or 1.0. Except for a somewhat steeper increase of the ratio $k_{A \Pi} / k_{\mathrm{HH}}$ when $J_{\mathrm{v}} / v^{0.8}$ is used as the variable on the abscissa, compared to $J_{\mathrm{v}} /$ $v$, the same dependence is found using different exponents $\langle a\rangle$.

Comparison of our results with those obtained by others is possible, e.g., when the dependence of $k_{\Delta \Pi} / k_{\mathrm{D}}$ on the $J_{\mathrm{v}} / v$ ratio in Fig. 6 is considered. Wijmans [13] found very similar results for Dextran T70 in the range $J_{\mathrm{v}} / v=(1-$ 2.5) $\times 10^{-5}$ while the work done by other researchers, as mentioned in the theoretical section, usually showed an experimental mass transfer coefficient which was smaller than the "theoretical" one $k_{\mathrm{th}}$ (i.e., $k_{\mathrm{HH}}, k_{\mathrm{D}}, k_{\mathrm{Gr}}$ or $k_{\mathrm{GL}}$ ). A more specific dependence of the mass transfer coefficient ratio on other parameters was not given and therefore can not be compared with our results.

When the plots of $k_{\Delta \Pi} / k_{\mathrm{th}}$ as a function of $J_{\mathrm{v}} / v$ are looked at in another way, the results do not seem to be very consistent any more: e.g., the influence of the cross-flow velocity can be regarded as almost random when the range of mass transfer coefficient ratios is given as a function of the cross-flow velocity (see Figs. 7 and 8). In Fig. 7 the $k_{\Delta \Pi} / k_{\mathrm{HH}}$ ratio varies from 0.2 to 0.7 for $v=1$ $\mathrm{m} / \mathrm{sec}$, and for $v=3 \mathrm{~m} / \mathrm{sec}$ the range is $k_{\Delta \Pi} / k_{\mathrm{HH}}=0.07$ to 0.7 . A slightly more specific range for each velocity can be given when the most extreme data points are left out. The ranges are then $0.4-0.7,0.3-0.6$ and $0.2-0.6$ for cross-flow 


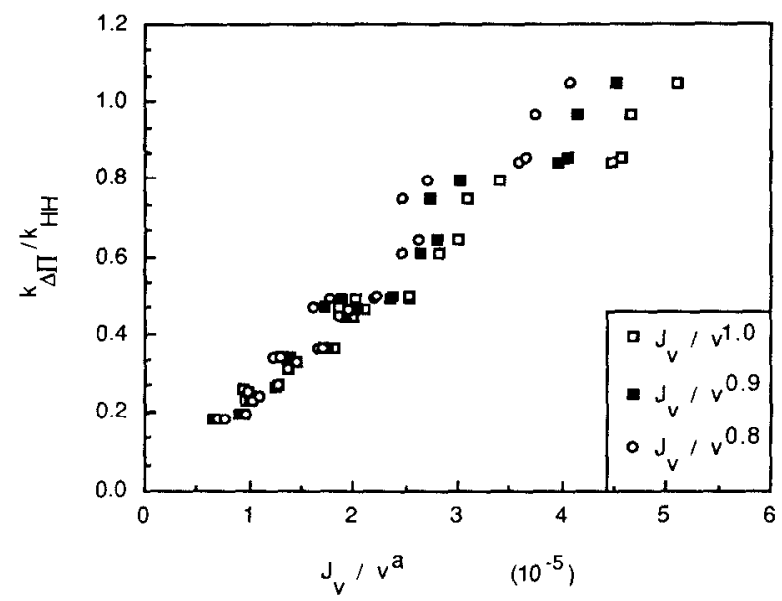

Fig. 18. Comparison of the $k_{A n} / k_{\mathrm{HH}}$ ratio as a function of the $J_{\mathrm{v}} / v^{a}$ ratio, in which the exponent $\langle a\rangle$ varied from 0.8 , via 0.9 to 1.0 . The experiments were performed with $B S A$ at $\mathrm{pH}=7.4$ in ultrafiltration system $\mathrm{B}, C_{\mathrm{b}}=1.0 \mathrm{~kg} / \mathrm{m}^{3}$.

velocities of 1,2 and $3 \mathrm{~m} / \mathrm{sec}$, respectively. Obviously there is no narrow range for the mass transfer coefficients when described as a function of the cross-flow velocity. This same conclusion can be drawn when the other process variables are studied. The use of a certain mass transfer coefficient ratio at a certain $J_{\mathrm{v}} / v$ ratio to predict fluxes therefore seems to be impossible because of the large spread in the experimental results.

The origin of this failure to describe the influences on the mass transfer coefficient correctly lies in the way in which the data are calculated and represented. This can be made clear as follows.

The experimental mass transfer coefficient is calculated via

$k_{A \Pi}=J_{\mathrm{v}} / \ln \left(C_{\mathrm{m}} / C_{\mathrm{b}}\right)$

while the theoretical mass transfer coefficient can be represented as:

$k_{\mathrm{th}}=\beta v^{a}$

When now a plot is made of, e.g. $k_{\Delta \Pi} / k_{\mathrm{HH}}$ as a function of $J_{\mathrm{v}} / v^{a}$, we find that the data in the plots can be generally described by a linear relationship:

$k_{\Delta \Pi} / k_{\mathrm{HH}}=\gamma J_{\mathrm{v}} / v^{a}$

So we find

$\left[J_{\mathrm{v}} / \ln \left(C_{\mathrm{m}} / C_{\mathrm{b}}\right)\right] / \beta v^{a}=\gamma J_{\mathrm{v}} / v^{a}$

or

$\ln \left(C_{\mathrm{m}} / C_{\mathrm{b}}\right)=1 /(\beta \gamma)$ 
Realizing that $\gamma$ is a constant for one combination of solute and ultrafiltration system and that $\beta$ should be practically constant (dependent on $D, \eta$ and $\rho$ only), the quantity $\ln \left(C_{\mathrm{m}} / C_{\mathrm{b}}\right)$ then has to be almost constant, which is not very realistic at first sight, since during an ultrafiltration experiment the applied pressures were varied from 2 to $6 \times 10^{5} \mathrm{~Pa}$. However, when the logarithmic concentrations at the membrane wall are considered, it appears to be feasible: when $C_{\mathrm{m}}=500 \mathrm{~kg} / \mathrm{m}^{3}$ the value of $\ln \left(C_{\mathrm{m}} / C_{\mathrm{b}}\right)$ is only $9 \%$ higher than in the case of $C_{\mathrm{m}}=300 \mathrm{~kg} / \mathrm{m}^{3}$, while a considerable difference in $\Delta \Pi\left(11.6 \times 10^{5}\right.$ $\mathrm{Pa}$ and $2.86 \times 10^{5} \mathrm{~Pa}$, respectively, for Dextran $\mathrm{T} 70$ ) and actual flux does exist. The conformity of the quantities plotted, as well as this very small dependence of the $\ln \left(C_{\mathrm{m}} / C_{\mathrm{b}}\right)$ value on the calculated concentration $C_{\mathrm{m}}$, probably is the origin of the bad agreement with our expectations. Since the main reason for our problem must be found in the equation $k_{\Delta \Pi}=J_{\mathrm{v}} / \ln \left(C_{\mathrm{m}} / C_{\mathrm{b}}\right)$, which is characteristic for the film model in general, no better solution can be expected for this theoretical inconvenience.

\section{Velocity variation method}

The results obtained using the velocity variation method must be evaluated rather differently: the slopes $1 / b$ in $k=b v^{a}$ in the plot of $\ln \left[\left(1-\mathscr{R}_{\text {obs }}\right) / \mathscr{R}_{\text {obs }}\right]$ versus $J_{v} / v^{a}$ are made equal for equal circumstances. Doing this results in a relationship for the experimental mass transfer coefficient $k_{\mathrm{vv}}$ which is proportional to $b$ and to the (chosen) quantity $v^{a}$. So, in fact, the two main parameters from which the mass transfer coefficient is composed are chosen within reasonable limits. The results for the velocity variation method using $v^{0.33}$ in the laminar case are encouraging (Fig. 13) and the comparison with the GraetzLeveque equation also: $k_{\mathrm{vv}} / k_{\mathrm{CL}} \approx 1.0$, indicating that the values are in the right order of magnitude. When $v^{0.50}$ is used the data show a less satisfying linear behaviour (Fig. 15), while the agreement with Grober's relation is also worse (Fig. 16). The results obtained for turbulent conditions show that the velocity variation method is applicable in this range as well. The use of Dextran T10 and T70 as solute in the systems mentioned above has one disadvantage: Dextrans have a broad molecular weight distribution $\left(M_{\mathrm{w}}=10,500\right.$ and 72,200 , while $M_{\mathrm{n}}=5100$ and 38,400 , respectively). The measured retentions will therefore be average retentions, which will make the evaluation less precise.

From the results given above, it will be obvious that quite a quantity of accurate data is needed to determine the mass transfer coefficient using the velocity variation method: a fairly large range of observed retentions and fluxes is necessary to obtain a reliable slope in the $\ln \left[\left(1-\mathscr{R}_{\mathrm{obs}}\right) / \mathscr{R}_{\mathrm{obs}}\right]$ versus $J_{\mathrm{v}} / v^{a}$ plot. The disadvantage of the need to employ incompletely rejecting membranes may be offset by a better description of the mass transfer coefficient.

When both the experimental and the mathematical errors (choosing an exponent $\langle a\rangle$ and calculating the slope $1 / b$ ) are taken into account the uncer- 
tainty in the magnitude of the mass transfer coefficient $k_{\mathrm{vv}}$ is rather large. Therefore in many cases the mass transfer coefficient may as well be described by the known, rather simple, mass transfer coefficient relations instead of employing the elaborate velocity variation method. These expressions will always be better than results obtained from the osmotic pressure method, which can hardly reflect the influence of changing experimental circumstances. The velocity variation method can still be very useful in cases which are hard to be described using the usual expressions, e.g. when the magnitude of one of the parameters (hydraulic diameter or diffusion coefficient etc.) cannot be estimated appropriately.

\section{Conclusions}

The determination of mass transfer coefficients from experiments is a rather complicated matter. When the osmotic pressure difference during an ultrafiltration experiment is used to determine the mass transfer coefficient $\left(k_{A I}\right)$, via the concentration at the membrane interface, an almost linear dependence of the $k_{\Delta \Pi} / k_{\mathrm{th}}$ ratio on the flux/cross-flow velocity ratio $\left(J_{\mathrm{v}} / v\right)$ is found. The dependence on the various process parameters (solute type, $C_{\mathrm{b}}, v, \Delta P$ and $d_{\mathrm{h}}$ ) is not very distinct, which must be a consequence of the theoretical conformity of the various equations used in the model. It is therefore impossible to obtain mass transfer coefficients when employing the osmotic pressure method for the evaluation of the flux equation.

The velocity variation method results in mass transfer coefficients which are constant over the entire $J_{v} / v^{a}$ range but with a substantial uncertainty. The exponent $\langle a\rangle$ in $k_{\mathrm{vv}}=b v^{a}$ has to be chosen in advance, while the value of $1 / b$ is calculated from the slopes in a plot of $\ln \left[\left(1-\mathscr{R}_{\mathrm{obs}}\right) / \mathscr{R}_{\mathrm{bbs}}\right]$ versus $J_{\mathrm{v}} / v^{a}$ and is a result of combining data at various pressures. Doing this can introduce a rather large uncertainty in the value of the mass transfer coefficient.

Neither of the methods mentioned is particularly reliable for determining the mass transfer coefficient, since the osmotic pressure method is very insensitive to changing parameters and the velocity variation method is rather sensitive to the chosen values of experimental parameters. The best experimental method for determining the mass transfer coefficient remains that of evaluation of the observed retention at varying velocities. Because of all the problems mentioned, the use of normal mass transfer relations can be as reliable as (and much easier than) the velocity variation method. The velocity variation method can probably be used in practice when one or more of the parameters needed in the conventional mass transfer coefficient relationships are unknown.

\section{Acknowledgements}

The authors gratefully acknowledge the experimental assistance of Ms. A. Gonlag, Mr. H.J.G. Haarman, Mr. R. Huwaë, Mr. P.J. Roeleveld and Dr. S. 
Stevanovic. We also thank Mr. M.J. van der Waal for the use of some of his data, and Wafilin B.V., Hardenberg, The Netherlands, for supplying us with the tubular membranes.

\section{List of symbols}

$\langle a\rangle$ exponent in $k=b v^{a}(-)$

$b \quad$ constant in $k=b v^{\text {a }}(-)$

$B_{n} \quad n$th virial coefficient $\left(\mathrm{m}^{3(\mathrm{n}-1)} \mathrm{kg}^{-\mathrm{n}+1}\right)$

$C_{\mathrm{b}} \quad$ concentration in the bulk $\left(\mathrm{kg} / \mathrm{m}^{3}\right)$

$C_{\mathrm{m}} \quad$ concentration at the membrane interface $\left(\mathrm{kg} / \mathrm{m}^{3}\right)$

$C_{\mathrm{p}} \quad$ concentration in the permeate $\left(\mathrm{kg} / \mathrm{m}^{3}\right)$

$D$ diffusion coefficient $\left(\mathrm{m}^{2} / \mathrm{sec}\right)$

$d_{\mathrm{h}} \quad$ hydraulic diameter $(\mathrm{m})$

$f \quad$ friction coefficient (-)

I ionic strength (N)

$J_{\mathrm{v}} \quad$ flux $\left(\mathrm{m}^{3} / \mathrm{m}^{2}-\mathrm{sec}\right)$

$J_{\mathrm{w}} \quad$ pure water flux $\left(\mathrm{m}^{3} / \mathrm{m}^{2}\right.$-sec $)$

$k \quad$ mass transfer coefficient $(\mathrm{m} / \mathrm{sec})$

$k_{\mathrm{D}} \quad$ mass transfer coefficient according to Deissler $(\mathrm{m} / \mathrm{sec})$

$k_{\mathrm{GL}} \quad$ mass transfer coefficient according to Graetz-Leveque $(\mathrm{m} / \mathrm{sec})$

$k_{\mathrm{Gr}} \quad$ mass transfer coefficient according to Grober $(\mathrm{m} / \mathrm{sec})$

$k_{\mathrm{HH}}$ mass transfer coefficient according to Harriott-Hamilton $(\mathrm{m} / \mathrm{sec})$

$k_{\Delta T} \quad$ experimental mass transfer coefficient calculated according to the osmotic pressure method $(\mathrm{m} / \mathrm{sec})$

$k_{\mathrm{vv}} \quad$ experimental mass transfer coefficient calculated according to the velocity variation method $(\mathrm{m} / \mathrm{sec})$

$L \quad$ length of a membrane module $(\mathrm{m})$

$L^{*} \quad$ length of the entry region in a membrane module $(\mathrm{m})$

$M \quad$ molecular weight $(\mathrm{kg} / \mathrm{kmol})$

M.W. molecular weight $(\mathrm{kg} / \mathrm{kmol})$

$M_{n} \quad$ number averaged molecular weight $(\mathrm{kg} / \mathrm{kmol})$

$M_{\text {w }} \quad$ weight averaged molecular weight $(\mathrm{kg} / \mathrm{kmol})$

$R \quad$ gas constant ( $\mathrm{J} / \mathrm{mol}-\mathrm{K})$

$\mathscr{R} \quad$ intrinsic retention coefficient $(-)$

$R_{\mathrm{m}} \quad$ hydraulic resistance of the membrane $\left(\mathrm{m}^{-1}\right)$

$\mathscr{R}_{\mathrm{obs}} \quad$ observed retention coefficient $(-)$

$T$ temperature (K)

$v \quad$ cross-flow velocity $(\mathrm{m} / \mathrm{sec})$

Greek letters

$\delta \quad$ thickness of the concentrated boundary layer $(\mathrm{m})$

$\triangle P \quad$ applied pressure $(\mathrm{Pa})$ 
$\rho \quad$ density $\left(\mathrm{kg} / \mathrm{m}^{3}\right)$

$\Pi \quad$ osmotic pressure $(\mathrm{Pa})$

\section{References}

1 J.G. Wijmans, S. Nakao, J.W.A. van den Berg, F.R. Troelstra and C.A. Smolders, Hydrodynamic resistance of concentration polarization boundary layers in ultrafiltration, J. Membrane Sci., 22 (1985) 117-135.

2 G. Jonsson, Boundary layer phenomena during ultrafiltration of dextran and whey protein solutions, Desalination, 51 (1984) 61-77.

3 W.F. Blatt, A. Dravid, A.S. Michaels and L. Nelsen, Solute polarization and cake formation in membrane ultrafiltration: causes, consequences, and control techniques, in: J.E. Flinn (Ed.), Membrane Science and Technology: Industrial, Biological and Waste Treatment Processes, Plenum Press, New York, NY, 1970, pp. 47-97.

4 V. Gekas and B. Hallström, Mass transfer in the membrane concentration polarization layer under turbulent cross flow. I. Critical literature review and adaption of existing Sherwood correlations to membrane operations. J. Membrane Sci., 30 (1987) 153-170.

5 D.E. Wiley, C.J.D. Fell and A.G. Fane, Optimisation of membrane module design for brackish water desalination, Desalination, 52 (1985) 249-265.

6 S. Nakao, T. Tanabe and S. Kimura, Mass transfer coefficient in ultrafiltration of macromolecular solutions, poster, 5th International Symposium on Synthetic Membranes in Science and Industry, Tübingen, F.R.G., September 2-5, 1986.

7 G. Belfort and N. Nagata, Fluid mechanics and cross-flow filtration: Some thoughts, Desalination, 53 (1985) 57-79.

8 R.B. Bird, W.E. Stewart and E.N. Lightfoot, Transport Phenomena, J. Wiley and Sons, New York, NY, 1960.

9 A.G. Fane, C.J.D. Fell and A.G. Waters, The relationship between membrane surface pore characteristics and flux for ultrafiltration membranes, J. Membrane Sci., 9 (1981) 245-262.

10 A.G. Fane, C.J.D. Fell, D. Wiley and R. McDonogh, Concentration polarization, mass transfer and fluid dynamics in membrane systems, Summer School on Engineering Aspects of Membrane Processes, Aarhus, Denmark, 1986.

11 R.L. Goldsmith, Macromolecular ultrafiltration with microporous membranes, Ind. Eng. Chem. Fundam., 10 (1971) 113-120.

12 G. Trägårdh and K. Ölund. A method for characterization of ultrafiltration membranes, Desalination, 58 (1986) 187-198.

13 J.G. Wijmans, The mass transfer coefficient in ultrafiltration, Ph.D. Thesis, Twente University of Technology, Enschede, The Netherlands (1984).

14 G. Schock, A. Miquel and R. Birkenberger, Characterization of ultrafiltration membranes: cut-off determination by gel permeation chromatography, J. Membrane Sci., 41 (1989) 5567.

15 E. Klein, P. Feldhoff and $T$. Turnham, Molecular weight spectra of ultrafilter rejection. II. Measurements on highly rejecting filters, J. Membrane Sci., 15 (1983) 245-257.

16 J. Kassotis, J. Schmidt, L.T. Hodgins and H.P. Gregor, Modelling of the pore size distribution of ultrafiltration membranes, J. Membrane Sci., 22 (1985) 61-76.

17 S. Nakao, S. Yumoto and S. Kimura, Analysis of rejection characteristics of macromolecular gel layer for low molecular weight solutes in ultrafiltration, J. Chem. Eng. Jpn., 15 (1982) 463-468. 
18 S. Nakao and S. Kimura, Analysis of solutes rejection in ultrafiltration, J. Chem. Eng. Jpn., 14 (1981) 32-37.

19 G. Jonsson and C.E. Boesen, Concentration polarization in a reverse osmosis test cell, Desalination, 21 (1977) 1-10.

20 S. Nakao, T. Nomura, H. Ohya and S. Kimura, Preprints, Workshop on Concentration polarization and Membrane Fouling, University of Twente, Enschede, The Netherlands, May $18-19,1987$.

21 V.L. Vilker, C.K. Colton and K.A. Smith, Concentration polarization in protein ultrafiltration. II. Theoretical and experimental study of albumin ultrafiltered in an unstirred cell, AIChE J., 27 (1981) 637-645.

22 G.B. van den Berg, J.H. Hanemaaijer and C.A. Smolders, Ultrafiltration of protein solutions; the role of protein association in rejection and osmotic pressure, J. Membrane Sci., 31 (1987) $307-320$.

23 G.B. van den Berg and C.A. Smolders, The boundary-layer resistance model for unstirred ultrafiltration. A new approach, J. Membrane Sci., 40 (1989) 149-172. 